\title{
Potentials and limitations for the use of accessibility measures for national transport policy goals in freight transport and logistics: Evidence from Västra Götaland County, Sweden
}

\author{
Anders Larsson ${ }^{1}$, Jerry Olsson ${ }^{2}$ \\ ${ }^{1}$ University of Gothenburg, Gothenburg, Sweden (email: anders.larsson@geography.gu.se) \\ ${ }^{2}$ University of Gothenburg, Gothenburg, Sweden and University of Oxford, Oxford, UK \\ (email: jerry.olsson@geography.gu.se)
}

Received: 28 October 2016/Accepted: 13 April 2017

\begin{abstract}
Swedish national transport policy treats freight transport as a major facilitator of economic development at all geographical levels. It is simultaneously noted that methods and data for business location and transportation are inadequate for following up transport policy objectives. This paper reports on a pilot study of the potential to develop accessibility measures to support and follow up policy objectives in the Swedish context. The accessibility concept and its practical application in concrete measures are discussed and problematized. Several practical examples from Västra Götaland County are used as illustrations. In terms of results, the study identifies several potentials and limitations of using accessibility measures to address freight transport issues. These measures' usefulness is driven mainly by the integration capability of transport and land use. This permits more complex questions and measures, supporting the integration between planning specializations. Limitations largely concern data availability and quality and the extent to which maps and measures can be communicated to non-experts. The concluding discussion highlights how the policy and governance context is central to understanding how best to utilize the potential strengths of the accessibility concept and related measures.
\end{abstract}

Key words: accessibility, freight transport, logistics facilities, transport policy

\section{Introduction}

Swedish national transport policy is intended to ensure that the transport system supports the country's economic development in a sustainable way, for example, by promoting the accessibility of logistics terminals, ports, and other transport infrastructure. It is simultaneously noted that methods and data for business location and transportation are inadequate for completely following up transport policy objectives in the field (Transport Analysis 2013a).

Shifts in the logistics sector have for quite some time illustrated a trend towards the consolidation of terminals, a trend expected to continue in the future (Hesse 2008, McKinnon 2009, Dablanc, Ross 2012, Sheffi 2012). This will lead to relatively fewer but larger units that may fundamentally change the accessibility of logistics services to 
businesses, especially those located outside major urban centres and transport corridors. It is therefore crucial that national and regional policymakers and planners better understand and follow up the shifting landscape of modern supply chains, as this underscores the importance of comprehensive efforts to coordinate land use, not only for logistics facilities but also other businesses that generate freight movements (Barysiene et al. 2015, David 2015, Sakai et al. 2015).

A key issue is the availability of data for both mapping current conditions and following change over time (Allen, Browne 2008). Freight flow data, for example, is only available at the crude geographical level of counties (Swedish Transport Administration 2013). One further explanation for the lack of comprehensive goals and targets is the heterogeneity of the freight transport market, in which each type of good has specific requirements and thus specific conditions and needs. This is sustained by the traditional institutional separation in which Swedish spatial planning is characterized by a two-level system based on the nation-state, at one level, and on local authorities with considerable autonomy, on the other. This system is not unique to Sweden (see David 2015 on land use planning in the United States). This has resulted in a division of spatial planning responsibilities, with strategic infrastructure and accessibility issues being handled at the national level, while local authorities are responsible for land-use planning, including business location. Although the last decade has witnessed growth in regional-level influence (Lindström 2007), there is still a substantial lack of coordination between actors at different geographical levels.

The Mobility Research Group at the Department of Economy and Society at the University of Gothenburg $^{1}$ has for several years worked on accessibility issues in personal transport, using a GIS-based model with high spatial resolution and connected to individual-level data (Elldér, Ernstson, Fransson, Larsson 2012). Several projects have been implemented, the most comprehensive one being implemented jointly with Västra Götaland Regional Planning Authority (Elldér, Gil Solá, Larsson 2012). This GIS-based model also has potential in the freight sector, as exemplified by recent research into city logistics and freight terminal utilization (Olsson, Woxenius 2012, 2014).

To pilot the methodological possibility of combining high spatial resolution with employment and industrial sector data, the Swedish government agency, Transport Analysis, has commissioned a project to test opportunities for better understanding regional patterns, accessibility potentials, and data requirements for accessibility analysis in freight transport (Olsson, Larsson 2016).

Within this context, the aim of this article is to introduce and examine the potentials and limitations of accessibility analysis for monitoring policy goals in freight transport. This scope can be specified in three research questions, as follows:

- What are the main strengths and weaknesses of the current accessibility approach relative to other similar concepts?

- How can accessibility measures be applied to freight transport problems?

- What are the most important strengths and limitations of accessibility analysis for monitoring transport policy goals?

The paper continues with a presentation and discussion of the accessibility concept and related measures, followed by a brief presentation of Swedish transport policy goals with a focus on freight transport. This presentation is then illustrated by examples of measures applied to Västra Götaland County. The results of the mapping and database analysis are brought together in the discussion section, which is followed by the presentation of conclusions.

\footnotetext{
${ }^{1}$ http://es.handels.gu.se/english/units/unit-for-human-geography/research/research-groups/mobility-research-group
} 


\section{From mobility to accessibility planning: concepts and measures}

\subsection{Introduction}

Recent decades have witnessed increasing travel and increasing levels of car dependence in cities worldwide (Handy 2002, Banister 2005, 2008). Mobility has become taken for granted in people's everyday lives and in business strategy development. This has profound implications for the flows and relationships that build cities and regions. Simultaneously, cities are experiencing a range of mobility-related problems, such as congestion, lack of safety, noise, and air pollution, all imposing societal costs and affecting business productivity (Bertolini 2005, Melo et al. 2009).

These are obviously problems whose solutions call for an integrated, holistic approach. Traditional planning perspectives often separate the fields of infrastructure, land use, and business development, treating them as "silos" with little or no coordination. The concept of accessibility brings together transport/mobility and land use, offering a useful framework for more integrated planning strategies (Geurs, van Wee 2004, Ferreira et al. 2012). It also offers a potentially powerful guide that planning practitioners can employ to develop and test effective strategies for building sustainable cities and regions (Straatemeier 2008).

\subsection{The accessibility concept}

In the following, we refer to accessibility based on the following definition: "The extent to which the land use-transport system enables (groups of) individuals or goods to reach activities or destinations by means of a (combination of) transport mode(s)" (Geurs, Ritsema van Eck 2001, p. 19). This definition is based on four components:

- Transportation: the cost (e.g., time or monetary costs) of moving goods or people physically to a destination including all modes of transport.

- Land use: the location and geographical distribution of potential origin and destination points, such as population density, jobs, services, customers, and warehouses.

- Time: access to facilities and activities varies during the day depending on, for example, the operating hours of suppliers and customers.

- Individual: individual values, opportunities, needs, and constraints represent important conditions for the broad application of the accessibility concept.

In an early application to spatial planning, Hansen (1959) broadly defined accessibility as: "the potential of opportunities of interaction". This suggests two contrasting definitions of accessibility, one addressing how points in a network relate to each other (i.e., access to potential opportunities from one specific starting point), and another depicting how all points are related to all other points on a surface (i.e., general spatial potential). Ingram (1971) later referred to this distinction as being between relative and integral accessibility, respectively. Our point of departure is the relative approach, since we are interested in accessibility for specific purposes, travelling to/from specific activity points. Before exploring accessibility measures in greater detail, we would like to draw attention to several related concepts.

\subsection{The relationship between accessibility, mobility, and proximity}

Accessibility as defined above is related to the concept of mobility, since movement is a means to achieve accessibility. It includes all forms of physical movement using or not using vehicles as well as virtual movement using communication technology. Historically, we have witnessed progression towards increasing car-based mobility over gradually longer distances in order to facilitate accessibility. However, given current discussion of mobility and sustainability (Banister 2008), it is important to highlight the opposite strategy, namely, accessibility through proximity.

Figure 1 illustrates in a simplified way two principal approaches to achieving good accessibility, i.e., spatial proximity and overcoming distance. Achieving good accessibility 


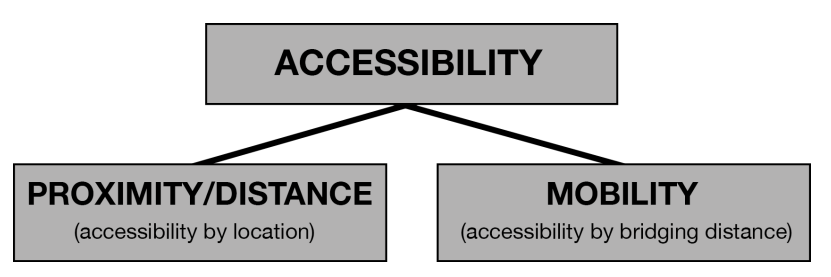

Source: Haugen 2012

Figure 1: The interrelationship between accessibility, mobility, and proximity

through proximity emphasizes the land-use component, with the importance of the location of points of production and consumption. Any improvement of accessibility then involves relocating either the origin or destination points, or both. The traditional policy solution to poor accessibility has been to concentrate on mobility by improving road infrastructure capacity, creating the potential to uphold reliable but potentially unsustainable transport systems over long distances.

This highlights a potential conflict between traditional transport-based planning and current land-use-based ideas of proximity- and non-car-based planning in cities (Newman, Kenworthy 2015). This debate has emanated from person-transport considerations but is as important for freight. We argue that this is one area where an accessibility approach provides a platform for the integration of transport and land use. It is important to note that normative measures are often needed in practical planning contexts (Páez et al. 2012), possibly leading to a situation in which opposing policy goals for transport and land use are present in the same accessibility measure.

These concepts and distinctions are fundamental, not only in an abstract theoretical sense but also in order to understand everyday planning problems. One example from personal transport is the so-called accessibility paradox (Haugen 2012, Haugen et al. 2012, Haugen, Vilhelmson 2013), in which measured reduced average travel times between residents and the nearest locations of important daily activities (e.g., schools and services) do not always correspond to shorter actual trip distances. Other factors and preferences (e.g., type of school and education) can be seen as more important than proximity. This illustrates that it is far from obvious that the relationship between accessibility, mobility, and distance is determined by a one-dimensional rational choice to minimize either distance or time. This is even more problematic in freight transport, in which decisions about route choice or terminal usage are made by several layers of actors and very rarely based on a shortest-distance logic (Melo et al. 2009).

Given this discussion, planning for improved accessibility in freight transport is complex. For example, it is important to critically examine for whom and where accessibility will be improved. Different firms at the same location might have very different accessibility needs and interests due to, for example, their types of goods, business sector, logistics management solution, customer density, and traffic congestion situation and to the effect of freight transport on local residents (Melo et al. 2009).

\subsection{Overview of accessibility measures}

To move from accessibility principles to implementation, we must look more closely at the most common accessibility measures. Geurs, van Wee (2004) identified four types of accessibility measures depending on the perspective or problem area considered: i) infrastructure-based, ii) activity-based (divided into location and space-time measures), iii) individual-based, and iv) utility-based measures. It is important to recall that, depending on the approach chosen, it is only possible to address a limited set of problems. Since this paper applies mainly location-based measures, we will emphasize these. However, a brief overview of other types of measures is given first.

An infrastructure approach to accessibility focuses on the properties of road, rail, bike, and walking networks, such as their connectivity and speed. These network properties provide a good indication of accessibility and mobility near where roads or railways and their nodes are located, but say less about accessibility over a wider hinterland. It is also 
difficult to measure, for example, the effect of increased road speed, as this is directly related to land-use factors such as population, jobs, and commuting (Geurs, Ritsema van Eck 2001).

Individual-based measures start at the individual level and consider the opportunities and limitations in performing activities at different locations during a given period, such as one day. The approach is largely based on a time-geographic approach (Hägerstrand 1970 ) in which the abilities of individuals or groups (e.g., households) to perform daily activities and projects are determined by individual and joint restrictions in time and space. Accessibility then becomes more complex than just being able to reach a certain point within a certain optimal distance or time. It also involves relationships with all other events and locations that need to be temporal-spatially coordinated during the day. When applied to freight transport and logistics, this approach might be used to better address limitations such as the opening hours of firms/suppliers/terminals and peak-hour congestion. This approach might be more applicable in a business context than in public land-use planning.

Based on economic utility theory, one can use businesses' valuations of the benefits of various alternative destinations as an accessibility measure. The assumed logic here is that decision makers make rational choices intended to maximize their own cost/benefit ratio. The advantage of this approach is that the measure has a strong theoretical coupling to economic theory. This is also its drawback, as considerable theoretical knowledge is required in order to understand such an abstract measure and how it can be implemented and communicated in practical planning (see La Paix, Geurs 2016).

\subsection{Location-based measures}

Location-based accessibility measures take into account both the transportation and the land-use components. In local or regional planning, this type of measure is considerably more relevant and is more widely applicable since it is directly linked to particular geographical areas and their demographic and socio-economic contexts. Such measures can range from straight-line distance or travel-time measures from one starting point to one or more destinations, to complex implementations of distance friction and the weighting of destination importance and competition.

The most straightforward measure is distance, either in absolute terms, such as the number of metres, or in relative terms, such as travel time. The aim is often to calculate either the number of potential customers or suppliers within a given catchment area or the closest destination(s) of interest. If we instead want to know how many warehouses (or other destinations) can be reached within a specific time interval, cumulative measures (i.e., contour or isochrone measures) are used. Breheny (1978) divided the accessibility of opportunities measure into three dimensions: starting points, destinations, and costs. By keeping one factor constant, it is possible to obtain a relatively easy-to-understand cumulative measure:

- Keeping costs constant measures the opportunities available within a certain cost in distance, time, or monetary terms; for example, the number of potential jobs reachable within a 30-minute trip.

- Keeping target points constant measures the cost of reaching a predetermined number of opportunities; for example, the average travel time across a region to reach $50 \%$ of the warehouses in that region.

- Keeping the starting point constant measures the potential opportunities based on variations in cost; for example, the number of warehouses within different travel-time intervals from a selected point.

These types of measures give results in the form of spatial distributions, allowing visualization in the form of influence fields or hinterlands. Figure 2 illustrates the spatial outcomes of these measures.

These metrics are useful in practical planning due to their relative simplicity and resulting communicability to a wider audience. This simplicity also presents problems, 

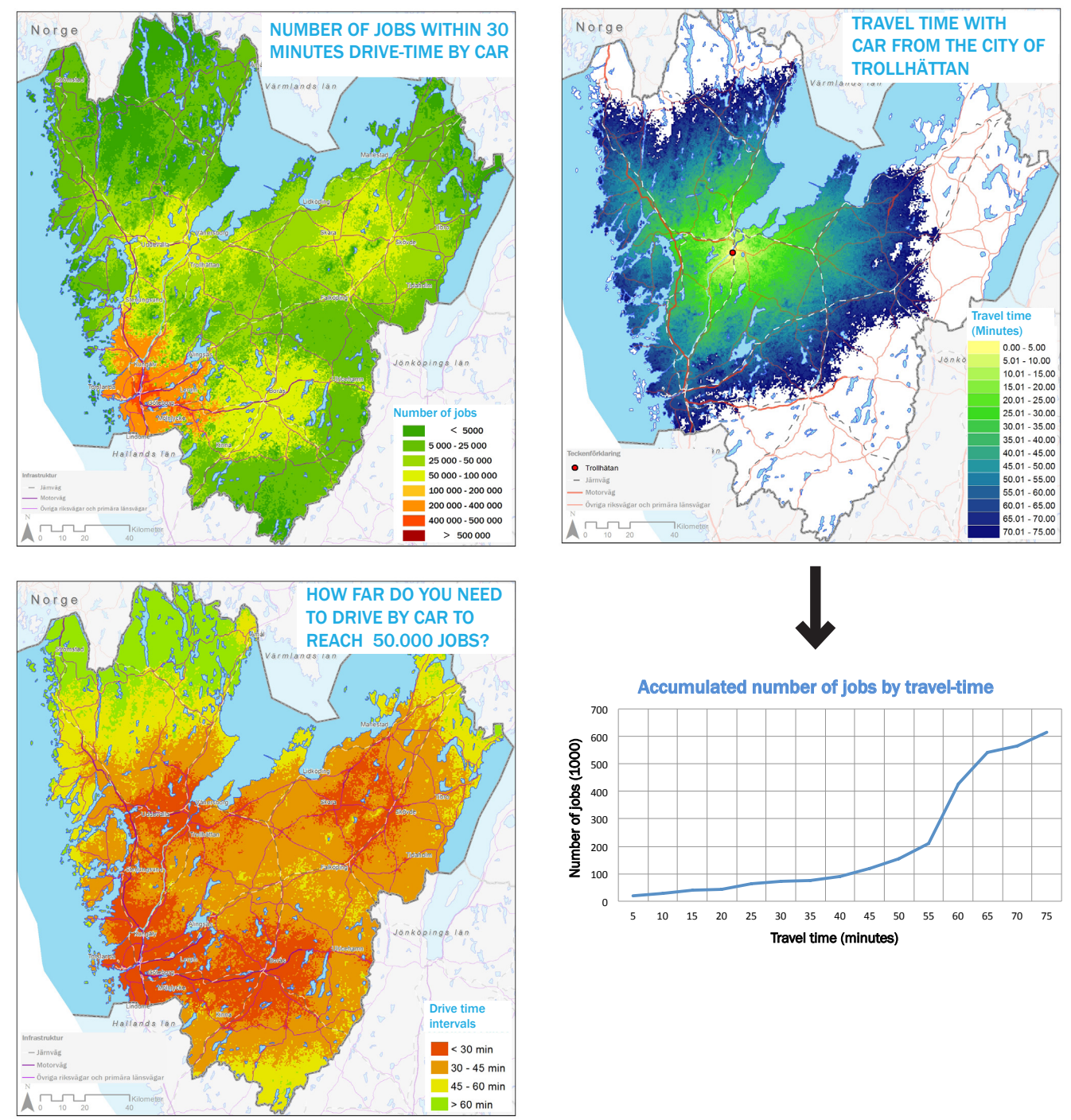

Source: sources: authors' calculations; road network, Swedish Transport Administration; other map data, Swedish Land Survey; socio-demographic data, Statistics Sweden

Figure 2: Illustrations of different accessibility measures using the same data: fixed cost (top left), constant target points (bottom left), constant starting point (top right), and potential jobs by travel time (bottom right)

however. An important limitation is that the used measures treat all target points as equally valuable, regardless of the travel time. It is important that the travel time and distance parameters be determined so as to reflect actual travel behaviour. For freight transport, this is a major limitation, since there is no direct equivalent to travel surveys in personal transport studies.

The value of distance can more realistically be calculated using functions to capture friction of distance, meaning that the farther away something is, the less its influence on the final result. The advantage of such metrics is that distance affects accessibility, enabling calculations based on empirical studies of actual travel behaviour. This yields more accurate and theoretically consistent results, which, however, may be difficult for outsiders to interpret. This approach also requires that function parameters be based on empirical travel surveys for them to be reliable for a specific region. 


\section{Swedish national transport policy goals for accessibility and freight trans- port}

The overall Swedish national transport policy objective states that the transport system should contribute to economic development throughout the country. In terms of accessibility, this requires good access to logistics terminals, ports, and other road/rail transport infrastructure. At the same time, concerning the monitoring of transport policy objectives and methods, it has been found that access to data on business location and transportation is inadequate (Transport Analysis 2013b,c).

One basic prerequisite for the creation of measures that contribute to the more efficient use of transport system resources is reliable information on the location of freight transport-intensive operation facilities. Authorities with overall responsibility for the follow-up of policy goals, such as Transport Analysis (2013b,c), need quantitative information on the accessibility of important logistical destinations, such as ports and logistics centres, to various industries. There is currently a lack of appropriate indicators, as the disaggregated data are of insufficient quality.

A question, then, is whose perspective should be taken into account? As logistics and freight transport comprise disparate activities with varied requirements and conditions, different actors' logic, behaviour, and priorities frequently counteract each other. There is a risk of sub-optimization in which all actors streamline their transportation needs based on the conditions governing their specific operations. When these actors are highly autonomous, individual decisions are made without paying attention to the entire logistics chain (Ministry of Enterprise and Innovation 2011).

The Energy Commission's final report states that long-term investments in infrastructure and other planning need to target the creation of conditions for a more energy-efficient transport system (SOU 2008). From a national perspective, therefore, knowledge of business locations and of the accessibility of key nodes and hubs (including ports and airports) is central, as both long-term planning and investment are expected to concentrate on fewer transport nodes and designated freight transport corridors, as illustrated in the following quotation (Swedish Transport Administration 2013):

In the national plan for the transport system, a strategic network for longdistance haulage is defined. The network includes a designated road/rail network, central intermodal terminals, ports, and airports. This network is considered to be of paramount importance for long-distance business freight transport. Therefore, Transport Administration actions should be concentrated on the strategic network. (Swedish Transport Administration 2013, p. 12)

This need to define a national core network follows partly because the distances within the country are great and partly because Sweden, as a major exporter, is very sensitive to the efficiency of increasingly spatially extended global transport networks. From a national perspective, industrial logistics costs are therefore central, from both the short-term competitive and long-term sustainability perspectives. However, the societal perspective has much broader significance, and the overall transport policy objective is to ensure economic efficiency for both business and citizens throughout the country. According to the Ministry of Enterprise and Innovation (2011), a priority is to increase the efficiency of freight transport and optimally use the existing infrastructure (increased infrastructure capacity cannot itself meet the entire expected increase in transport demand). From a societal perspective, therefore, logistics must be recognized as transportation activity wherein capacity, traffic environment (i.e., safety), accessibility, and energy consumption are taken into account for all users - including passengers. At the same time, these considerations need to be balanced by a good economic and business climate. Taken together, this calls for clear indicators for monitoring community investments in transportation and land use. 


\section{Accessibility measures and their application in freight transport: exam- ples from Västra Götaland County}

\subsection{Method, material, and limitations}

Accessibility measures and maps are calculated using purpose-built software initially developed for personal transport to combine advanced transport modelling of public transport with GIS functionality (Berglund 2001). This accessibility tool combines georeferenced data with information about the transport system and travel options. It enables the computation of accessibility by both car and public transport of many potential supply points, such as amenities and workplaces.

For this study we have used only the capabilities related to movement along the road network. The computations were based on calculated travel times between $500 \times 500$-metre cells, allowing analysis beyond administrative divisions. For a more in-depth description of the tool functionality see Elldér, Ernstson, Fransson, Larsson (2012) and Larsson et al. (2014).

Each cell contained information on the number of logistics terminals and food-sector firms. Logistics terminals are defined as facilities for the reception, delivery, consolidation, distribution, and storage of freight in the transportation process. Food-sector firms comprise facilities covered by the Swedish industry classification code SNI 10, which covers the production of foodstuffs. This allows us to link driving times, land uses (or location patterns), and economic indicators on the production side of the logistics-sensitive food sector. We are aware that the distribution side of the food sector is also highly relevant in terms of logistics restructuring. However, a lack of detailed data on retailers and large-chain internal terminals limits the potential to include such information in this illustrative case. This issue is elaborated on in sections 5 and 6 .

The data used in the analysis is drawn from several sources, as follows:

1. Road network data, including speed limits for calculating driving time, was supplied by the Swedish Transport Administration's National Road Database (NVDB) and captures the situation in September 2014.

2. Data on logistics terminals, including their exact locations, was updated by the authors based on a previous study by the government agency Traffic Analysis (WSP 2013). The services and activities that terminals offer can be captured only partially using statistical industry codes. These terminals may range from storage-only facilities to complete logistics centres incorporating a wide range of complementary services. Substantial time was spent manually qualifying the function of terminals.

3. Data on multimodal rail-road terminals, including location and capacity, was collected by the authors from company and public authority websites.

4. Locations of food-sector firms were extracted from the internal GILDA longitudinal database comprising official register data provided by Statistics Sweden. Individuals are linked to their workplaces, making it possible to identify the type of activity associated with all workplaces in the region.

The measures are calculated based on certain conditions and limitations due to incomplete data or limitations in the accessibility model. In this study, logistics terminals are limited to those open to all potential commercial customers. This definition is applied because it reflects the true geographical potential. We can find many additional facilities within company-internal logistics systems. However, these are not potential service points for outsiders even if located within reach according to accessibility calculations.

In some analyses we refer to large terminals, which are terminals with annual turnovers of SEK 100 million in 2014 (equivalent to USD 12.5 million). This demarcation is relevant in order to identify sites with enough capacity to supply customers with a variety of services.

As discussed elsewhere in this paper, cumulative accessibility measures are dependent on the setting of time limitations. In this case, 60 minutes of driving time is used as the threshold in several maps. This is based on the principle of centrality, whereby a 
terminal's hinterland comprises roughly $100 \mathrm{~km}$ (Rodrigue et al. 2013, p. 135). Exactly where the line is established on a commercial basis may vary between carriers.

A further distinction concerns potential customers. Different business sectors have very different requirements in terms of distances, terminal facilities, etc. In this study, we use the food industry as a proxy for logistics-intensive industries, representing the part of the economy that is dependent on flexible and frequent logistics chains for daily activities and that could potentially use the terminals. One important limitation of the calculations is that they include only terminals and food-sector production plants in Västra Götaland County. This limitation was made due to the very time-consuming process of identifying logistics terminals, elaborated on in section 5. Since both logistics providers and terminals compete, this limitation creates uncertainty as to the results in border regions. This is especially significant in the eastern part of the region, where a significant market is reachable by 30 minutes of driving.

We would also like to raise the issue of data categorization on maps. Visual perceptions, and hence the analytical values, of datasets are highly dependent on the selection of appropriate classes and categories (Evans 1977). For this paper, we selected classes according to the principle of simplicity in communication with non-expert groups; for example, travel times are divided into 15-minute intervals. It is important to note that other classification schemes might reveal a more extreme hierarchical pattern in the data (Jiang 2013), being more suitable for research questions comparing highly accessible areas with less accessible ones.

\subsection{Accessibility measures based on driving time to nearest facility}

The most straightforward geographical measure is driving time to the nearest terminal. Figure 3 shows the driving time to the nearest terminal, regardless of its size or function. The map clearly illustrates how virtually every part of the region has access to a terminal within 30 minutes.

The map in Figure 4 illustrates the calculated accessibility to large terminals expected to provide the range of services needed for customers not part of corporate logistics networks, such as those of Volvo or IKEA. Using only the major terminals as destinations, differences in driving time become more pronounced. Moreover, it is possible to discern several corridors along major highways with short travel times. This also illustrates the usefulness of disaggregated spatial units: the use of more aggregated spatial units, such as municipalities, could cause the corridor effects shown in the map to be overlooked.

Driving time is useful due to its uncomplicated form. However, to benefit from accessibility analysis, there is a need to add the land-use component. This is illustrated in Figure 5 by the number of companies in the food industry located within different driving-time intervals.

Adding the potential number of users in the logistics-sensitive food sector illustrates the concentration and co-location of warehouses and food-sector firms. Half of the firms are under 15 minutes from the nearest terminal and more than $80 \%$ can be reached within 60 minutes. The difference between large terminals and all terminals widens with increased travel time, but does not exceed $10 \%$.

The use of driving time as a measure has several advantages, mainly because the result in minutes is an absolute value and very easy to communicate. This indicator is directly related to everyday freight transport issues such as delivery time and precision. A further advantage is that it is relatively easy to calculate, needing only two datasets: road network and terminal locations. This makes it affordable to calculate and, from a data supply perspective, it is relatively easy to collect longitudinal datasets in order to monitor changes over time.

There are also limitations to using driving time as a measure. Its simplicity means that it addresses only a very specific question. For following up the Swedish national transport policy objectives, however, this measure is insufficient on its own. A further drawback is the use of travel time without weighting. For personal transport measures, it is common to add weights to the points of attraction and to use distance decay functions for the travelling. Here the logic is that the larger the city, the greater the attraction, and conversely, the farther away, the greater the resistance. This procedure is supposed to 


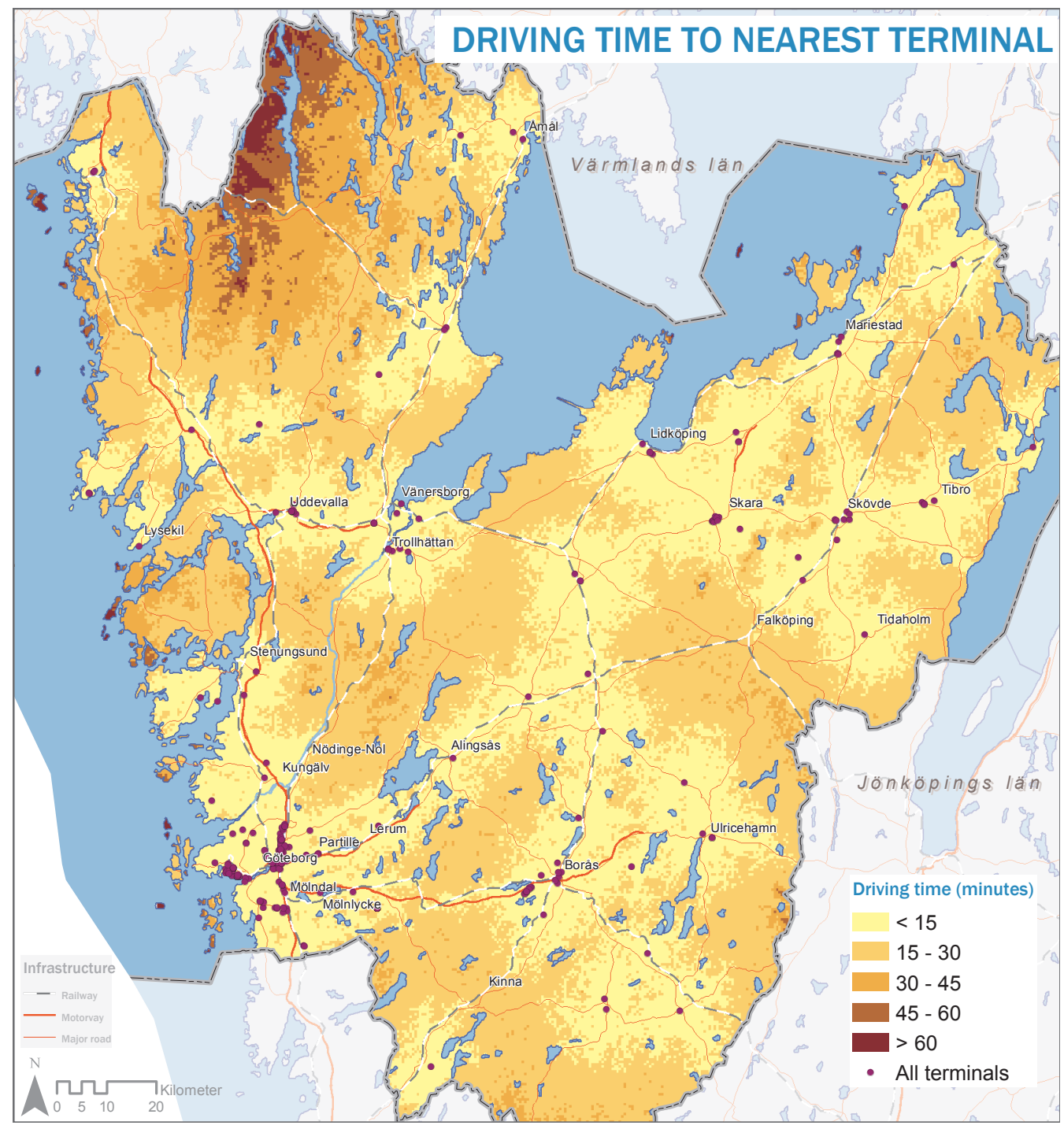

Figure 3: Accessibility in terms of driving time to the nearest terminal

make the analysis more realistic in relation to travel behaviour. The problem in freight transport calculations is lack of knowledge (mainly due to lack of primary data) of how goods actually move and of the criteria for the choices made. More knowledge of the "travel behaviour" of freight would be needed in order to determine whether, for example, the nearest terminal is actually a valid measure in real everyday situations.

\subsection{Measures based on potential accessibility and catchment areas}

While the measure used in Figures 3 and 4 illustrates accessibility from a transport buyers' perspective, the logic can be reversed and instead used to investigate the potential catchment areas of terminals, measured as the number of destinations reachable within a specific time. In this case, we have chosen 60 minutes of driving time.

The main advantage of this measure is that it connects infrastructure and space via potential, providing a clear basis for assessing what areas meet a certain objective or minimum requirement level. This measure is also relatively easy to communicate. Compared with the driving time indicator, catchment areas permit us to follow up municipalities' and regions' competitive potential in terms of how well they are situated in the terminal landscape.

However, one important limitation is the fact that the measure considers all destinations 


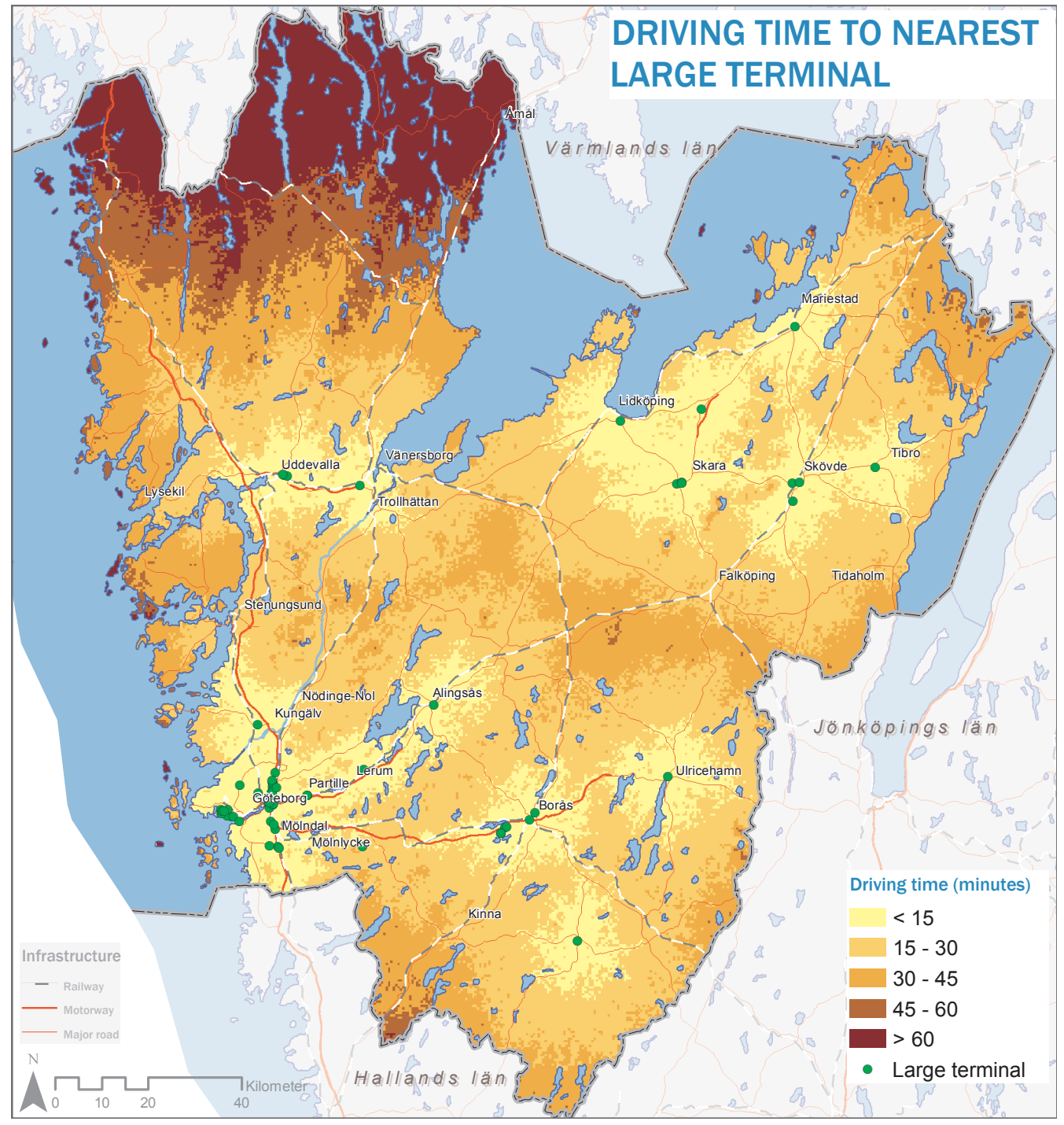

Figure 4: Accessibility in terms of driving time to the nearest large terminal, defined as having annual turnover exceeding SEK 100 million

equally valuable regardless of driving time. A terminal located a 60-minute drive away from the starting point is given the same value as a terminal located 5 minutes from the customer. Again, it is important to set driving time and distance parameters based on empirical data, to reflect real behaviour as well as possible.

Transferring the concept of travel behaviour to freight transport is complex, since the choice of route or terminal is usually not determined by the driver, but instead results from the commercial need to transport a product. The choice of starting point (e.g., firm) and destination point (e.g., terminal) then depends on several factors, such as business arrangements limiting what terminals to use and goods requiring special treatment (e.g., frozen foods). This brings the discussion to the question of constructing weights for destinations and travel distance to model accessibility more realistically.

\subsection{Weighed measures}

Some form of weighting is traditionally used in transport models (de Dios Ortúzar, Willumsen 2011) to create better theoretical approximations of actual travel behaviour. Destinations located farther away then become more costly to reach, while the more important the destination is, the more attractive it becomes. Translated into the terms 


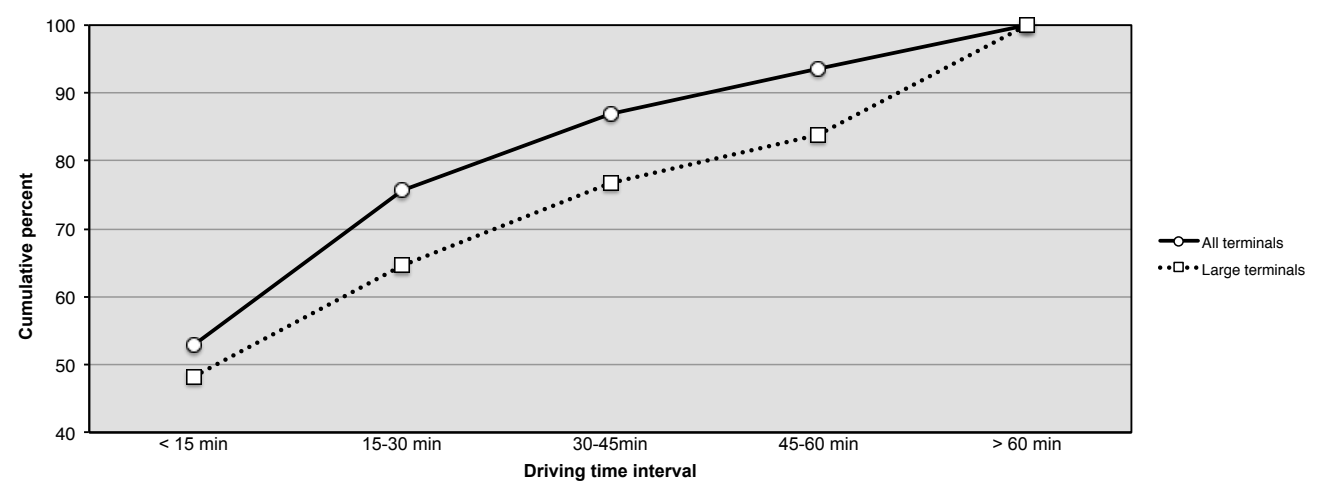

Source: authors' calculations; firm data from GILDA

Figure 5: Cumulative share of food industry companies within different driving-time intervals from all terminals and large terminals

of Figure 3, accessibility would not be determined solely by the travel time in minutes, but the minutes would become "longer" the farther one travels due to distance decay. In addition, the importance of each terminal in terms of, for example, size and turnover, would further influence the degree of attractiveness.

However, this approach has at least two important limitations. As noted above, we currently know very little about the "travel behaviour" of freight and therefore have limited empirical data with which to weight both distance decay and the relative influence of destinations. What we know is that transportation to and from terminals is part of increasingly complex supply chains. This means that the choice of terminal for a single shipment is determined by decisions much earlier in the process than when the transport is performed. A second limitation is the usefulness of the calculation results. Since both the distance and target point affect travel time based on various often nonlinear functions, the end result cannot be interpreted in minutes; instead, there is a need to construct relative weighted accessibility measures.

Figure 7 illustrates the driving time to the nearest terminal weighted by the terminals' annual turnovers. The weights are set using a simple linear logic in order to clearly illustrate the effects of a weighted measure. Small terminals with large hinterlands clearly illustrate poor relative accessibility. These results indicate that choosing the nearest terminal is often unrealistic, as exemplified by the two terminals located in Götene (see inset map in Figure 7). The southern terminal has a high turnover and is therefore favourably weighted, while the northern terminal has a considerably lower weight. In practice, there is only 1 minute of driving time between the two terminals, so all potential customers in the northern area of very extensive "weighted travel time" can easily choose the southern option instead. One method to solve the problems associated with treating the nearest terminal as the default would be to calculate the travel time to the nearest two or three terminals. A problem with this approach would arise in areas with very few terminals where the second or third terminal could be located very far away.

It is also possible to use weighting in analysing potentials at different locations. Figure 8 illustrates this with a calculation of accessibility weighted by terminal turnover, where higher turnover implies a higher potential service level. The map shows the aggregated total terminal turnover accessible within 60 minutes of driving time. The actual aggregated values for highly accessible areas become astronomical, obviously with no connection to the real values of points in the region. The advantage of this measure is that it qualifies the differences between areas with many terminals in absolute terms, but differing greatly in size. The pattern in Figure 8 does not differ significantly from that in Figure 6, but the values are much more dispersed and thus highlight the significance of being nearer large facilities, rather than just any facility. 


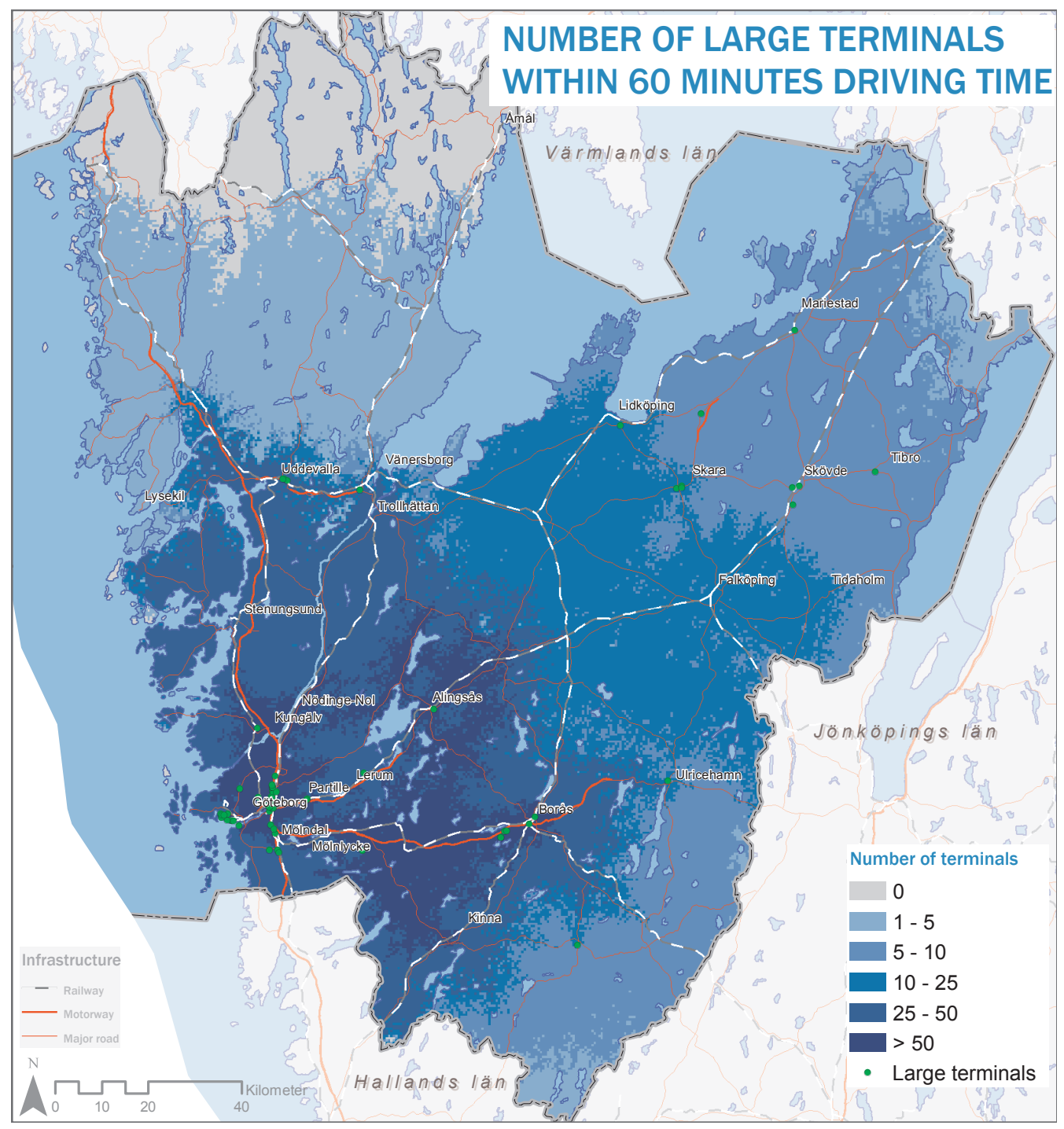

Figure 6: Number of large terminals accessible within 60 minutes of driving time

\subsection{Spatial aggregation of detailed measures}

Analysis and measures have so far been visualized with a spatial resolution of 500 metres. This resolution shows intra-regional variations very well, but is less suitable for follow-up at the national level. Since national targets are already using municipalities as the spatial unit for monitoring transport policy objectives, we propose using a method of spatial aggregation and combining measures into one single composite measure. The following exercise should be regarded as an example for discussion, rather than as a complete and finished measure ready for application.

The starting point for the measure will be the municipality. The first step is to assign a centre point to each municipality where trips start or finish depending on the measure. We suggest that centre points should be calculated based on the spatial pattern of logistics-sensitive industry. In this case, the weighted centre point for the food industry is our proxy for logistics-intensive industry.

We then select three measures meant to complement each other:

1. Terminal proximity: driving time from the municipal centre to the nearest terminal weighted by the terminal's economic turnover - This measures the extent to which the municipality has large terminal capacity in its immediate vicinity.

2. Terminal potential: the sum of the terminal's financial turnover earned within 60 


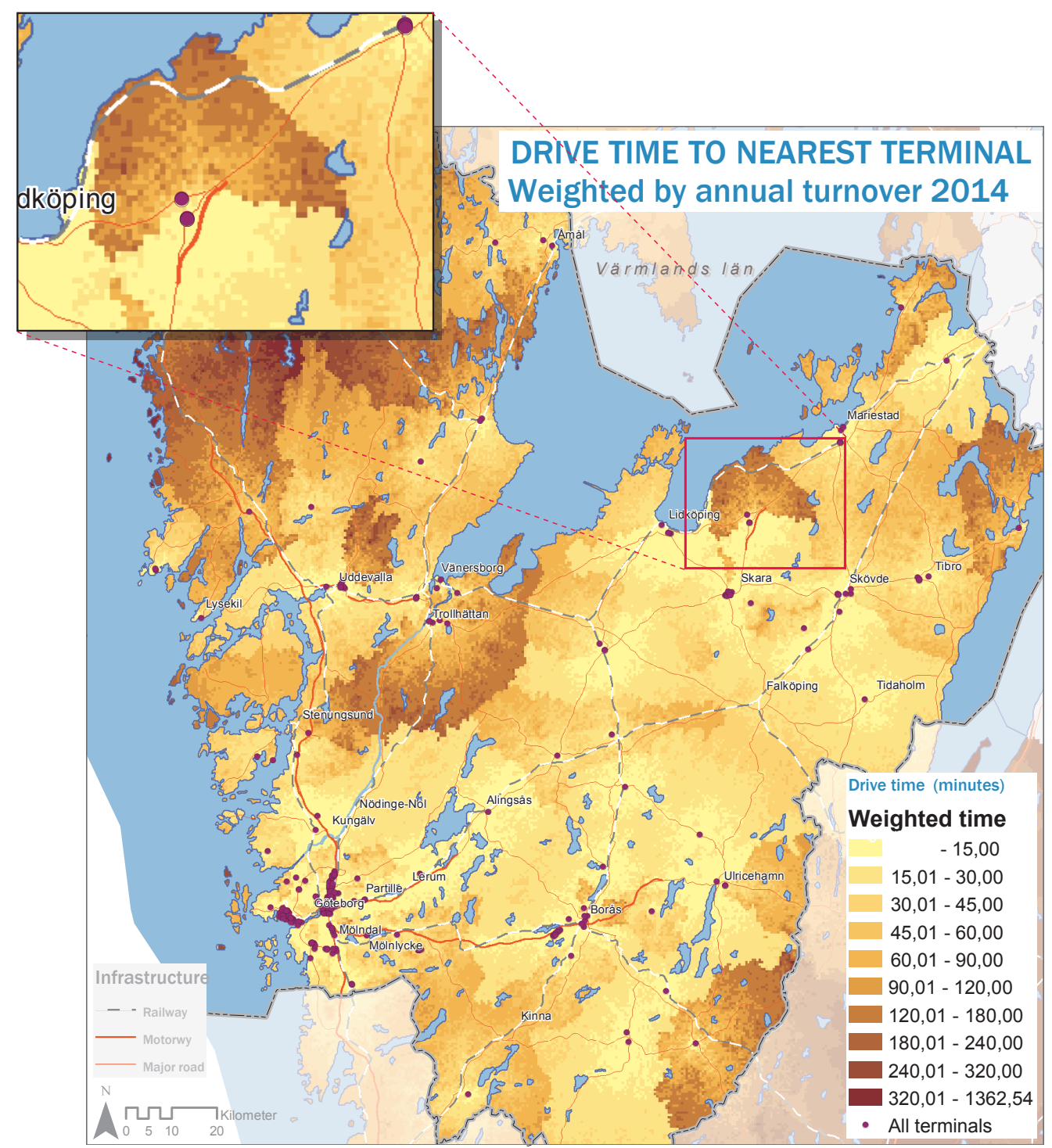

Figure 7: Accessibility measured as driving time to nearest terminal, weighted by annual turnover of terminal

minutes of driving time from the municipal centre - This complements terminal proximity and indicates the potential attractiveness of the area for the localization of logistics-intensive businesses.

3. Road/Rail combination potential: the total weighted value of the size of intermodal terminals reachable within 60 minutes of driving time from the municipal centre This indicates the potential accessibility of good combined transport opportunities.

Each indicator is mapped in Figure 9. Indicator 1, the proximity indicator, produces more heterogeneous results than do the cumulative potential indicators illustrated in the two other maps. Accessibility is very good in the Gothenburg metropolitan region and along the major transport corridors. Also apparent are single peripheral municipalities each with a large terminal.

Indicator 2 reflects the dominance of the Gothenburg region due to the concentration of large terminals there. Again, note that the maps include only terminals located in Västra Götaland County, putting outlying municipalities at a relative disadvantage. Indicator 3 clearly shows the importance of Gothenburg; this particularly applies to the large multimodal terminals in the port, which weigh heavily in this context. 


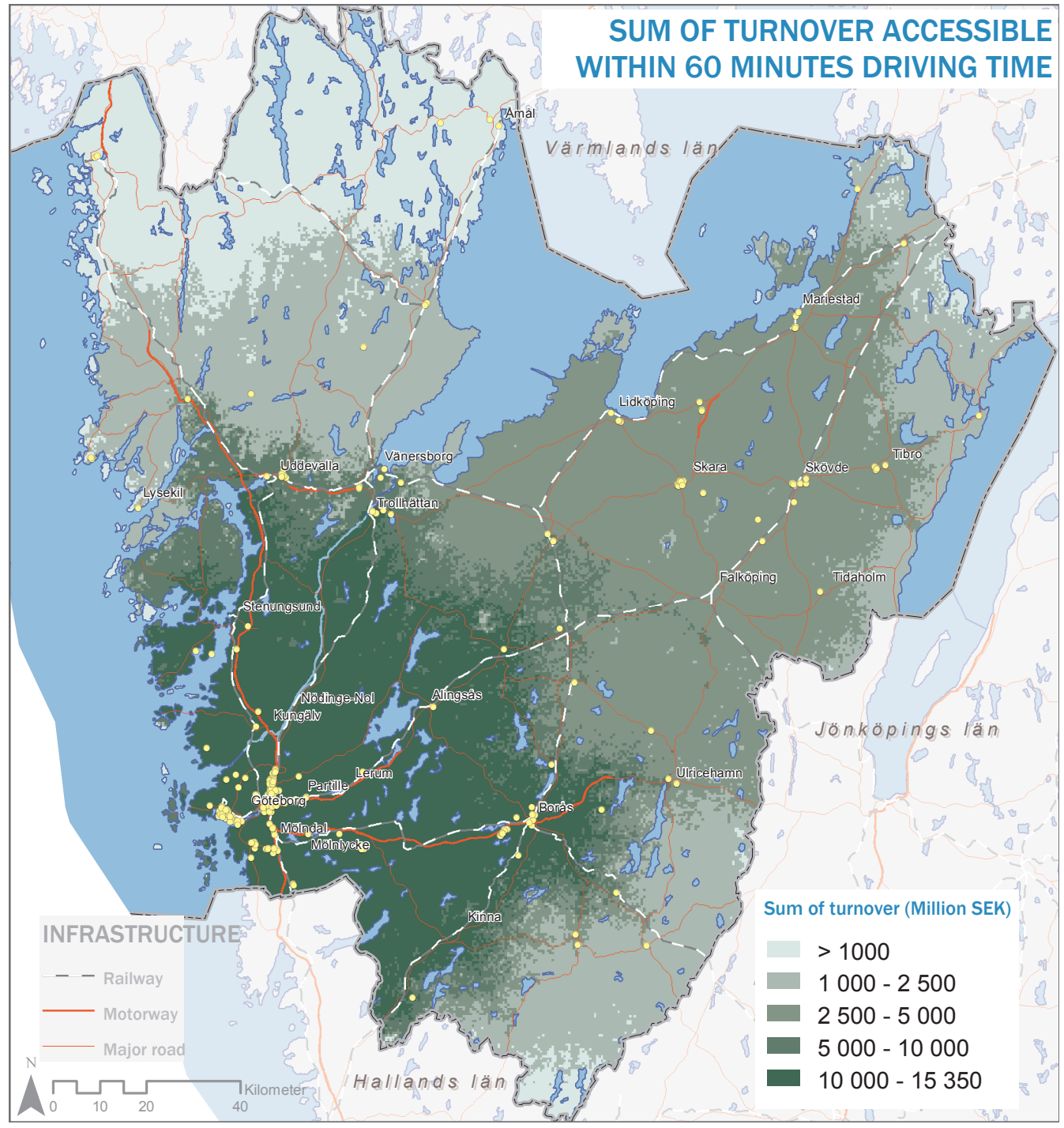

Figure 8: Aggregated terminal turnover accessible within 60 minutes of driving time

The measures are relatively straightforward in that they are related to driving time measured in minutes. However, merging the three indicators into one is problematic since they are weighted differently and their numerical outputs differ greatly. One way to achieve this would be to calculate the share of each municipality based on the total of the region and then add the relative numbers. Another method would be to rank all the municipalities for each indicator and then merge the three ranking figures to form a common ranking score. This method will be used here based on the simplicity of communicating and follow-up over time.

Figure 10 shows the summary score per municipality, illustrating how the major transportation corridors in the region have better access to logistics services than do their neighbouring municipalities. It is also very clear how proximity to the county's main urban centre of Gothenburg exerts an influence. One can see an inner and an outer ring of municipalities with very good accessibility located around Gothenburg.

\section{Discussion}

The main advantage of the accessibility concept in freight transport planning and policy lies in its integration of transportation and land use. Current approaches often focus on just one of the two. Transport planning is mostly concerned with network-related aspects 

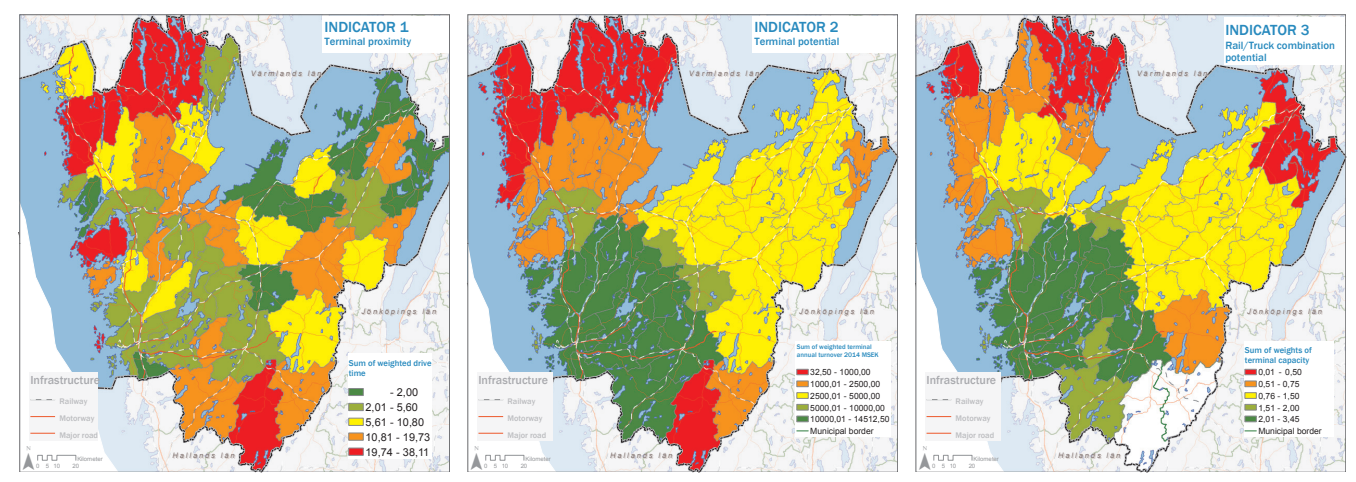

Figure 9: Illustration of the three municipality-based indicators. Left to right: terminal proximity, terminal potential, and rail/truck combination potential

of mobility efficiency such as speed, connectivity, flows, congestion, and parking. Land-use planning, in contrast, traditionally addresses issues related to human activities and their spatial outcomes, such as housing, economic development, and leisure activities. The accessibility concept offers a way to link these fields, taking a step towards a more integrated planning process (Bertolini 2005). It supports the link between transport/mobility and social sustainability issues (Lucas 2012), since changes in mobility always have different spatial accessibility outcomes for different groups in society. Being able to combine two areas of planning into one also entails potential problems. Obviously, an extra degree of complexity results when dealing with transport and land use simultaneously. Measures of accessibility will undoubtedly be more multi-dimensional than, for example, population density or traffic flows. There is also an added component when evaluating accessibility change over time, since both transportation and land use can change simultaneously over the same period.

Given the potential for the accessibility approach to support integration in planning, how can this approach be applied specifically to freight transport? This is an important question since freight and personal transport differ substantially in this respect. Unlike personal transport, freight transport is driven by derived commercial demand emanating from the business sector. Choice of transport mode or route is the combined result of a logistics chain comprising several frequently conflicting dimensions, such as cost, reliability, and scale economies. Accessibility in freight transport is much more likely to be a business matter, while in personal transport it directly mirrors the potentials of individuals and their everyday lives in different locations. Having this distinction in mind is important when asking questions about accessibility levels, for whom and where. On the other hand, accessibility measures may also be used with specific planning questions in mind, to understand how different groups in different places are, for example, influenced by new investment in logistics terminals and infrastructure.

Even a basic travel-time map provides a wealth of information. The use of "real time" measured in minutes without weighting or model calculations constitutes a potentially powerful outcome due to ease of interpretation: no expert knowledge is needed to conclude that ten minutes is twice as long as five minutes. This makes simple accessibility measures useful tools in communication between professional groups, such as planners and logistics business representatives, as well as with the general public in matters of spatial planning to promote more sustainable and inclusive urban regions. This is not to argue that accessibility should replace other well-proven methods. However, as an additional approach, it provides views that might foster more informed debate and ultimately better decisions.

Based on the data collection and accessibility mapping exercise described here, several key strengths and limitations can be identified. Data availability and quality is the major area of concern. However, specific institutional and business issues relating to the freight transport sector are also important, as are questions regarding the context in which accessibility measures are being used. Each of these areas will be discussed below. 


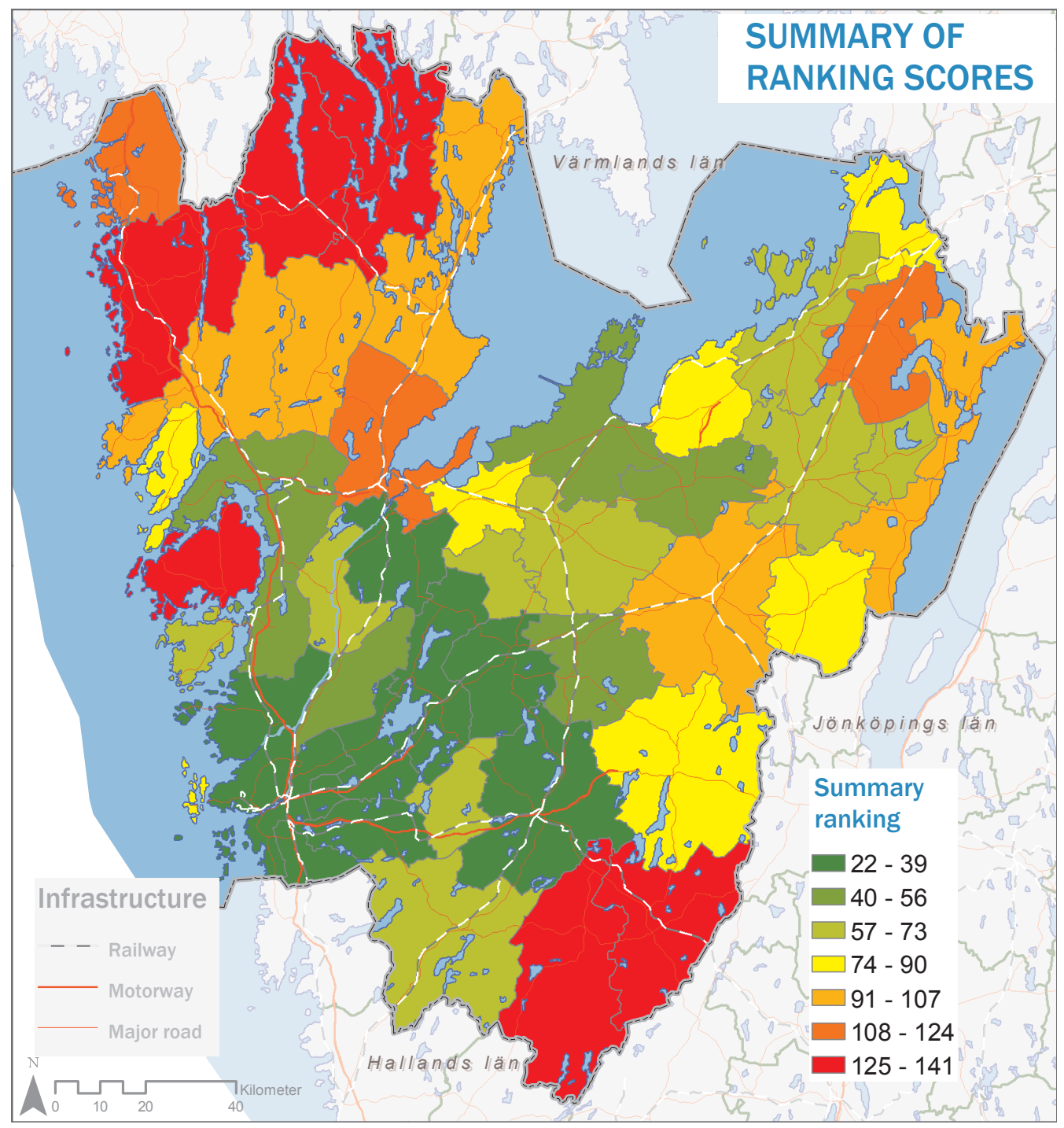

Figure 10: Illustration of the summary ranking scores per municipality

The single most pressing concern is data access and quality. Constructing useful measures of accessibility for freight transport calls for information about points of supply and demand and their locations. Since the industry encompasses a vast array of goods and destinations, it is insufficient to identify just any terminal or any customer. A basic need is business sector information in order to identify customer segments and terminal functions and to discern service levels.

The terminal data for the example maps shown here were produced in two stages. First, an automated search script scanned the official national company register (WSP 2013). Second, this was followed by a time-consuming manual check by the authors, resulting in a $25 \%$ increase in the number of terminals, many reclassifications, and the identification of multiple counting of the same terminal used by different companies. We estimate that officially available firm-level data are insufficiently reliable for accessibility analysis without considerable manual updating, possibly supported by enhanced models for the automated searching of business registers.

Specific surveys offer a potential way forward. In the case of freight transport, there is a lack of open statistical data on how goods actually flow, who is transporting goods, and what kinds of goods these are. This information is central to building more advanced models of accessibility in which the "travel behaviour" of the goods is taken into account. The assumption that the nearest terminal is the one selected is unrealistic, as indicated 
by current projects collecting detailed information on freight flows (see Dablanc 2013, Giuliano et al. 2015).

The question of terminal access is related partly to data availability and partly to logistics chain strategies. Many transport terminals are integrated into company-internal flows of material. For example, large retail chains or manufacturing firms employ their own global high-precision logistics systems with large warehouses. These are unavailable to local firms and should therefore not be part of an accessibility analysis of the general potentials of a specific area. From a local land-use planning perspective, however, these activities contribute to both employment and negative environmental effects.

The resolution of the maps in this study is very high. Results are presented using 500-metre cells across the region, which has proven very useful for planning problems at the local and regional scales (Elldér, Larsson 2011). However, this resolution is too high for following up policies and investments at the national level: technical limitations restrict the handling of large datasets, and complementary data are lacking at such a detailed level.

Finally, we would like to emphasize the user side of accessibility measures. So far most of the discussion has been from the producer side, focusing on measures, data, and output. However, if a non-expert user such as a planner or politician cannot fully understand the maps and measures, there is a significant communication problem that seriously limits the usefulness of these tools (te Brömmelstroet 2010). This exemplifies a wider issue regarding the sometimes contradictory relationship between scientifically sound models and the usefulness of their results in non-expert environments. The desire to model reality has often resulted in attempts to create big models that quickly become so complex that their outcomes cannot be used without expert knowledge (Lee 1973, Geertman, Stillwell 2004). This is not to say that modelling should be abandoned, but we would like to emphasize the user and the context in which results are implemented.

\section{Conclusion}

The use of accessibility measures to support policy and planning for freight transport and urban development offers a promising and long-needed potential for cross-sectoral integration between the fields of transport and land use. However, to fully exploit this potential several barriers must be overcome. This paper has identified a few problem areas, such as data availability and quality as well as the complexity and communicability of measures. Though these are definitely challenges in themselves, they are technical and relatively specific and can be addressed with a carefully devised research programme. Instead, we would like to highlight the wider and more complex policy and planning context for the application of accessibility analysis, especially potential tensions between actors and interests in the freight transport sector and its relations with society in general and urban development issues in particular.

While personal transport and accessibility can be related directly to individuals and their everyday activities as well as to society and planning on multiple scales, freight transport is primarily an activity organized by the private business sector. This has important implications for the usefulness of the accessibility concept and the methods of implementing it. Figure 11 illustrates this as two routes from an overall national policy objective towards more detailed planning objectives and implications in the private business and public realms. We are aware that the distinction between private and public is far from straightforward and binary; however, for reasons of clarity, we will pursue this division in the following discussion.

The point of departure is the black box in the centre of the figure containing the formulation of the overall national transport policy objective. In transport and land-use planning, this has predominantly been treated as the downward, stepwise application of national policy to regional and local levels of public planning. The more detailed the level, the further from the national goal and the more important the local context is, or should be, in terms of how to interpret and implement policies in a democratic and inclusive way. In contrast, if we follow the upward route, policies play a much more marginal role in the everyday running of businesses. Their main objective, emanating from commercial, 


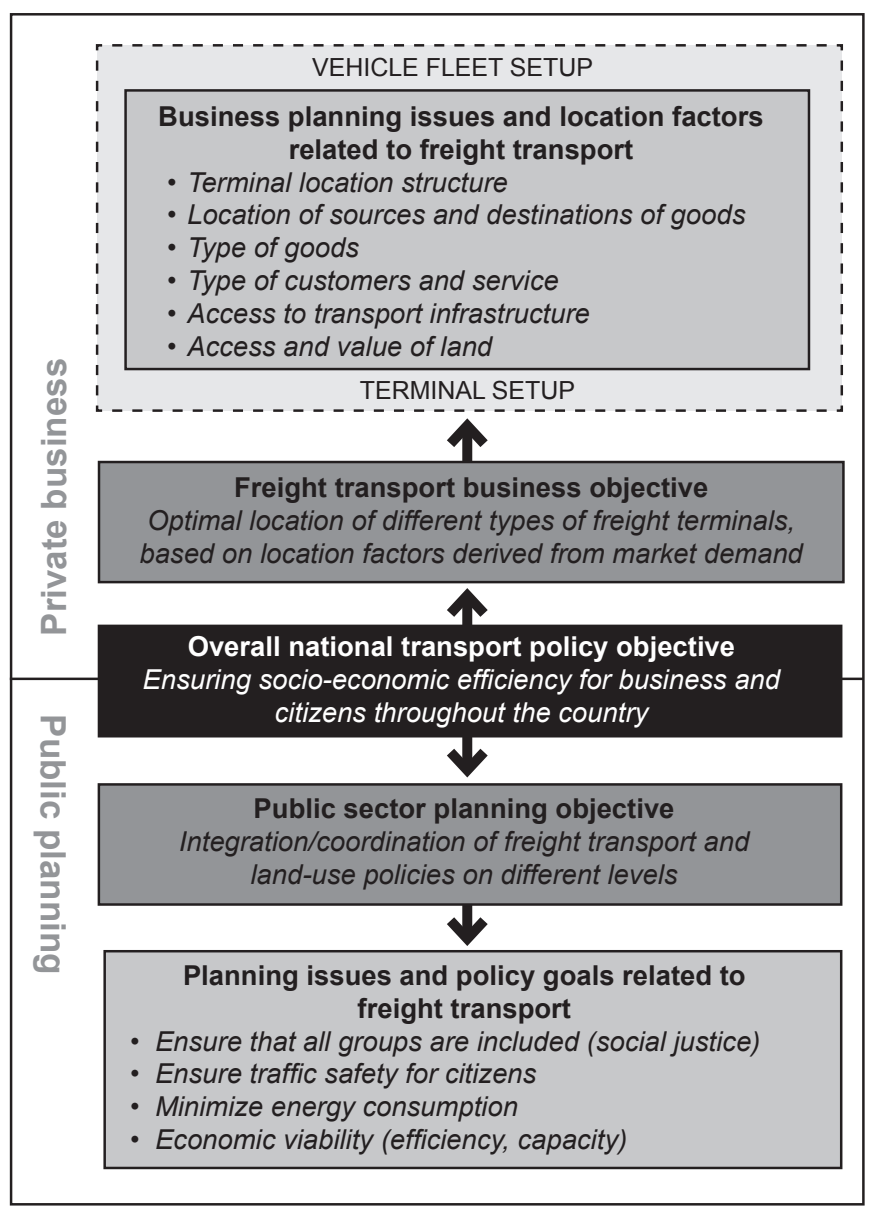

Figure 11: How the national transport policy objective can be implemented in the business and public planning spheres

market pressures, is to provide services that customers are prepared to pay for in order to earn a profit and meet the company's and shareholders' financial targets.

We might say that from the national policy objective, the scope and impact will widen downwards in the public planning sphere and narrow upwards in the business context. This is not to say that the two spheres are unconnected or exist in two parallel worlds, as urban planning is constantly interacting with freight transport and vice versa. However, accessibility analysis and accessibility questions affect the two spheres in different ways.

Imagine, for example, an expanding international port located in an expanding urban area. What would be the relevant accessibility question to ask in order to follow up the national goal? From a business competitiveness perspective, it might be interesting to know whether companies can access more and better logistics services over time in the region or whether more companies can reach the port within the same time as an effect of new infrastructure investment. For an urban planner or local policy maker in the same port city, the question of the accessibility of jobs, schools, and recreation for citizens might be at the top of the agenda. The same infrastructure that supports increased terminal and port accessibility could create physical barriers, including noise and pollution, that decrease the accessibility of other amenities for citizens.

The combination of transport and land-use components is the main strength of the accessibility concept. However, for its productive use we must be careful about its implementation context. The above example illustrates how different groups might have conflicting interests in the same space. To better measure and follow up urban transport land-use policies and potential conflicts, we must develop our knowledge, mainly about the private business sphere. The "travel behaviour" of goods and locational decision making 
in the freight sector are keys to implementing the accessibility concept as a long-needed integration tool in order to better understand the interplay between freight transport and its urban context.

\section{References}

Allen J, Browne M (2008) Review of survey techniques used in urban freight studies. Transport studies group, University of Westminster, London

Banister D (2005) Unsustainable Transport: City Transport in the New Century. Routledge, London

Banister D (2008) The sustainable mobility paradigm. Transport Policy 15: 73-80. CrossRef.

Barysiene J, Batarliene N, Bazaras D, Ciziuniene K, Griskeviciene D, Griskevicius AJ, Lazauskas J, Maciulis A, Palsaitis R, Vasiliauskas AV, Vasiliene-Vasiliauskiene V (2015) Analysis of the current logistics and transport challenge in the context of the changing environment. Transport 30: 233-241

Berglund S (2001) GIS in transport modelling. Phd dissertation. Department of Infrastructure, Royal Institute of Technology, Stockholm, Sweden

Bertolini L (2005) Cities and transport: Exploring the need for new planning approaches. In: Albrechts L, Mandelbaum S (eds), The network society: A new context for planning. Routledge, Oxford

Breheny M (1978) The measurement of spatial opportunity in strategic planning. Regional Studies 12: 463-479. CrossRef.

Dablanc L (2013) Commercial goods transport, Paris, France. Case study prepared for global report on human settlements 2013 http://www.unhabitat.org/grhs/2013

Dablanc L, Ross C (2012) Atlanta: a mega logistics center in the Piedmont Atlantic Megaregion. Journal of Transport Geography 24: 432-42. CrossRef.

David PD (2015) Factors affecting municipal land use cooperation. Land Use Policy 42: 170-182. CrossRef.

de Dios Ortúzar J, Willumsen LG (2011) Modelling Transport. John Wiley \& Sons, Chichester. CrossRef.

Elldér E, Ernstson U, Fransson U, Larsson A (2012) Analysverktyg för tillgänglighetsberäkning med bil och kollektivtrafik i Västra Götaland. Slutrapport. occasional papers 2012:1. Department of Human and Economic Geography, University of Göteborg, Göteborg, Sweden

Elldér E, Gil Solá A, Larsson A (2012) Spatial inequality and workplace accessibility. Environment and Planning A 44: 2295-2297

Elldér E, Larsson A (2011) Improving regional transport accessibility planning. A GISbased methodology based on micro-level register data. Regional Studies International Conference. 18-20 April 2011. Newcastle upon Tyne, UK

Evans I (1977) The selection of class intervals. Transactions of the Institute of British Geographers 2[1]: 98-124. CrossRef.

Ferreira A, Beukers E, te Brömmelstroet M (2012) Accessibility is gold, mobility is not: A proposal for the improvement of transport-related Dutch CBA. Environment and Planning B 39: 683-697

Geertman S, Stillwell J (2004) Planning support systems: an inventory of current practice. Computers, Environment and Urban Systems 28: 291-310. CrossRef. 
Geurs K, Ritsema van Eck J (2001) Accessibility measures: review and applications. Rivm report 408505 006. Netherlands National Institute of Public Health and the Environment, Bilthoven, The Netherlands

Geurs K, van Wee B (2004) Accessibility evaluation of land-use and transport strategies: review and research directions. Journal of Transport Geography 12: 127-140. CrossRef.

Giuliano G, Dablanc L, Rodrigue J, Seo S (2015) Building the database. Final report project no.: 15-1A. metroFreight Center of Excellence, University of Southern California, Los Angeles, California, USA

Handy S (2002) Accessibility- vs. mobility-enhancing strategies for addressing automobile dependence in the U.S. European Conference of Ministers of Transport, Brussels

Hansen WG (1959) How accessibility shapes land use. Journal of the American Institute of Planners 25: 73-76. CrossRef.

Haugen K (2012) The accessibility paradox. Gerum 2012:1. Department of Geography and Economic History,University of Umeå, Umeå, Sweden

Haugen K, Holm E, Strömgren M, Vilhelmson B, Westin K (2012) Proximity, accessibility and choice: A matter of taste or condition? Papers in Regional Science 91: 65-84. CrossRef.

Haugen K, Vilhelmson B (2013) The divergent role of spatial access: the changing supply and location of service amenities and service travel distance in Sweden. Transportation Research A 49: 10-20. CrossRef.

Hesse M (2008) The City as a Terminal. The Urban Context of Logistics and Freight Transport. Ashgate, Aldershot

Hägerstrand T (1970) What about people in regional science? Regional Science Association Papers XXIV: 7-21. CrossRef.

Ingram DR (1971) The concept of accessibility: A search for an operational form. Regional Studies 5: 101-107. CrossRef.

Jiang B (2013) Head/tail breaks: A new classification scheme for data with heavy-tailed distribution. The Professional Geographer 65[3]: 482-494. CrossRef.

La Paix L, Geurs K (2016) Train station access and train use: a joint stated and revealed preference choice modelling study. In: Geurs K, Patuelli R, Ponce Dentinho T (eds), Accessibility, equity and efficiency: Challenges for transport and public services. Edward Elgar Publishing, Cheltenham. CrossRef.

Larsson A, Elldér E, Vilhelmson B (2014) Accessibility atlas to analyse regional accessibility to labour in the food sector. In: Brömmelstroet M, Silva C, Bertolini L (eds), Assessing usability of accessibility instruments. Report 2 from the COST Action TU1002, European Science Foundation and the COST Office, Brussels

Lee DBJ (1973) A requiem for large scale models. Journal of the American Institute of Planners 39: 163-178. CrossRef.

Lindström A (2007) Territorial governance in transition. Regional and Federal Studies 17: 499-508. CrossRef.

Lucas K (2012) Transport and social exclusion: Where are we now? Transport Policy 20: 105-113. CrossRef.

McKinnon A (2009) The present and future land requirements of logistics activities. Land Use Policy 26: 293-301. CrossRef.

Melo MT, Nickel S, Saldanha-da Gama F (2009) Facility location and supply chain management - A review. European Journal of Operational Research 196: 401-412. CrossRef. 
Ministry of Enterprise and Innovation (2011) Framtidens citylogistik. Rapport från arbetsgruppen för citylogistik inom Logistikforum. Näringsdepartementet, Stockholm, Sweden

Newman P, Kenworthy J (2015) The End of Automobile Dependence. How Cities are Moving Beyond Car-Based Planning. Island Press, Washington DC

Olsson J, Larsson A (2016) Accessibility to terminals in Västra Götland - A pilot study. PM 2016:9, Transport Analysis, Stockholm (in Swedish) http://www.trafa.se/globalassets/pm/pm-2016_9-tillganglighet-till-terminaler-i-vastra-gotaland--en-pilotstudie.pdf

Olsson J, Woxenius J (2012) Location of freight consolidation centres serving the city and its surroundings. Procedia - Social and Behavioral Sciences 39: 293-306. CrossRef.

Olsson J, Woxenius J (2014) Localisation of freight consolidation centres serving small road hauliers in a wider urban area: barriers for more efficient freight deliveries in Gothenburg. Journal of Transport Geography 34: 25-33. CrossRef.

Páez A, Scott DM, Morency C (2012) Measuring accessibility: positive and normative implementations of various accessibility indicators. Journal of Transport Geography 25: 141-153. CrossRef.

Rodrigue J, Comtois C, Slack B (2013) The Geography of Transport Systems. Routledge, Abingdon

Sakai T, Kawamura K, Hyodo T (2015) Locational dynamics of logistics facilities: Evidence from Tokyo. Journal of Transport Geography 46: 10-19. CrossRef.

Sheffi Y (2012) Logistics Clusters. Delivering Value and Delivering Growth. MIT Press, Cambridge

SOU - Statens Offentliga Utredningar (2008) Vägen till ett energieffektivare Sverige. Slutbetänkande av Energieffektiviseringsutredningen, SPU 200:110

Straatemeier T (2008) How to plan for regional accessibility? Transport Policy 15: 127-137. CrossRef.

Swedish Transport Administration (2013) Godskartläggning i VG. Rapport 2013:151. Trafikverket, Borlänge

te Brömmelstroet M (2010) Equip the warrior instead of manning the equipment: Land use and transport planning support in the Netherlands. Journal of Transport and Land Use 3: 25-41

Transport Analysis (2013a) Indikatorer för en transportpolitisk måluppföljning - hur tillgänglighet påverkar konkurrens- och utvecklingskraft. Rapport 2013:2. Trafikanalys, Stockholm, Sweden

Transport Analysis (2013b) Indikatorer för en transportpolitisk måluppföljning - hur tillgänglighet påverkar konkurrens- och utvecklingskraft. Trafikanalys: Stockholm, Sweden

Transport Analysis (2013c) Transportarbete 1950-2012. Trafikanalys: Stockholm, Sweden. http://www.trafa.se/sv/Statistik/Transportarbete/

WSP (2013) Methodology for the identification of freight terminals in Sweden. Internal report (in Swedish). WSP, Stockholm, Sweden 